\title{
WHITMAN AND THE CIVIL WAR
}

\section{EDITOR'S NOTE:}

In this special double issue, the Walt Whitman Quarterly Review presents major new work on Whitman and the Civil War by two well-known Whitman scholars, Jerome Loving and M. Wynn Thomas. Loving's essay is from the opening chapter of his forthcoming major critical biography of Whitman, Walt Whitman: The Song of Himself, to be published by the University of California Press. Loving offers a rich context for understanding Whitman's vacillating attitudes toward the Civil War. Thomas's essay investigates Whitman's fascinating and revealing responses to the weather during the Civil War and suggests the way weather worked as a trope for Whitman. Thomas also investigates how weather carried meaning during the Civil War period in very different ways than it does in our era of weather forecasting. Finally, we present a piece by Thomas David Lisk that is part fiction, part fact-a collage of materials that imagines Whitman as an old man in Camden, New Jersey, thinking back on his Civil War experiences. This piece is part of a set of such writings by Lisk about Whitman, and it adds to the growing number of striking fictional treatments of Whitman's Civil War experiences, evidenced most recently by Chris Adrian's short story in The New Yorker (October 6, 1997) about Whitman at Union Square Hospital. All of this work enhances our developing understanding of Whitman's complex interactions - as poet as person - with what he preferred to call the War to Preserve the Union. 